\title{
Effect of Adhesive Thickness and Concrete Strength on FRP-Concrete Bonds
}

\author{
Julio C. López-González ${ }^{1}$; Jaime Fernández-Gómez²; and Enrique González-Valle ${ }^{3}$
}

\begin{abstract}
The use of fiber-reinforced polymer (FRP) composites for strengthening, repairing, or rehabilitating concrete structures has become more and more popular in the last 10 years. Irrespective of the type of strengthening used, design is conditioned, among others, by concrete-composite bond failure, normally attributed to stress at the interface between these two materials. Single shear, double shear, and notched beam tests are the bond tests most commonly used by the scientific community to estimate bond strength, effective length, and the bond stress-slip relationship. The present paper discusses the effect of concrete strength and adhesive thickness on the results of beam tests, which reproduce debonding conditions around bending cracks much more accurately. The bond stress-slip relationship was analyzed in a cross section near the inner edge, where stress was observed to concentrate. The ultimate load and the bond stress-slip relationship were visibly affected by concrete strength. Adhesive thickness, in turn, was found to have no significant impact on low-strength concrete but a somewhat greater effect on higher strength materials.
\end{abstract}

\section{Introduction}

Bond failure in the composite material in bending- or shearstrengthened beams often controls bearing capacity of the strengthened member. Debonding failure of RC beams strengthened in bending by externally-bonded composite laminates (EB-FRP) usually does not develop inside the adhesive layer, but either in the concrete substrate or along the tensile reinforcement; i.e., failure involves detachment of the cover.

A good deal of research has been conducted over the last 10 years to calculate stress at the interface in pursuit of a better understanding of bond failure. A number of analytical solutions can be found in the specialized literature. The simplest stems from pure shear analysis, in which interfacial stresses are related to FRP-concrete slippage. This was the approach used by Teng et al. (2006) and Wang (2006a). A numerical model for this method was developed by López et al. (2011).

A second, more complex case addresses the interfacial stresses generated in bending-strengthened beams under shear forces and bending moments. The characteristic common to most analytical solutions is the assumption that materials exhibit linear elastic behavior. Recent studies in this regard have been authored by Tounsi and Benyoucef (2007), Yang et al. (2007), and Tounsi et al. (2009). Another assumption shared by these solutions is that stress is constant across the adhesive. In solutions put forward in the literature (Rabinovich and Frostig 2000; Shen et al. 2001) to take the variation in stress across the adhesive into account, they naturally lead to more complex solutions.

Along with analyses based on pure shear only, the literature also addresses solutions that use the bond stress-slip relationship to analyze interfacial shear stress in beams under transverse loads (Oller 2005; Wang 2006a, b).

The need to experimentally measure FRP bonding to concrete has induced the scientific community to develop test methods for that purpose. Experimental campaigns, in turn, have given rise to models for predicting bond strength, effective length, and the stress-slip relationship. One of the various classifications in place, based on the stress state of the interface, defines the following test modes: mode I (normal stress), mode II (shear stress), and mixed mode (normal and shear stress).

The procedure for mode I is a direct tensile type test, the sole standardized test for determining FRP-concrete bond strength. Detailed specifications on its application can be found in ASTM D7522/D7522M-09 (ASTM 2009) and ACI 440.3R-04 (ACI 2004).

The two most popular methods for testing mode II are listed subsequently.

- The single shear bond test consists of applying tensile force to the FRP laminate. This is the test procedure most frequently used by researchers to measure bond strength. A number of recent studies based on this method have been published, specifically, by Yao et al. (2005); Sharma et al. (2006); Ferracuti et al. (2007); Toutanji et al. (2007), and Mazzotti et al. (2009).

- The double shear bond test is similar to the single shear test except that tensile force is applied to two laminates bonded on opposite sides of the concrete member. This bond test has been used less widely than the preceding procedure because of its greater complexity. It has nonetheless been applied by 
a number of researchers, including, most recently, Foster and

Khomwan (2005); Leung et al. (2006), and Cao et al. (2007).

Mixed mode bond tests, consisting of beam-type tests or special configurations (Horiguchi and Sacki 1997; Perera et al. 2004; Wan et al. 2004; Guo et al. 2005) in which both normal and shear stresses are induced at the interface, have been studied less thoroughly. Horiguchi and Saeki (1997) reported that the bond strength values found with beam-type testing lay in-between the results observed with tensile tests, which yielded higher, and shear tests, which yielded lower values.

The beam-type test proposed and used here to determine the bonding characteristics of FRP at varying concrete strengths and adhesive thicknesses was similar to the test used for measuring steel reinforcement to concrete bonding conditions. In light of the findings, this test was deemed to be usable to study different types of adhesives and application methods, because it reflects the behavior of FRP in strengthened beams more accurately than the aforementioned standard procedures. It may also prove to be useful to study bonding in concrete surfaces damaged by fire or other aggressive conditions.

\section{Experimental Procedure}

A total of 30 beam-type specimens were prepared to the geometry described in Spanish and European standard UNE-EN-10080 (UNE-EN 2006) (type A beam) for this study. The inner edge of each half-beam was beveled, as shown in Figs. 1 and 2, to avoid an overconcentration of stresses. Five specimens were tested for each combination of concrete strength $(20,30$, or $40 \mathrm{MPa})$ and adhesive thickness (two). The test beams were strengthened with 50-mm-wide, 1.2-mm-thick pultruded prefabricated FRP plates glued to the member with an epoxy adhesive. The test groups are summarized in Table 1 . The mechanical properties of the materials are listed in Table 2.

The surface was chipped before applying the adhesive. Adhesive thickness was kept to measure by placing two wooden guides on each side of the beam. Following manufacturer instructions, the plate was glued to 28-day concrete specimens along a length of $22 \mathrm{~cm}$ to leave sufficient space between the hinge and the edge of the plate. Resin was spread over the concrete in amounts that prevented the appearance of voids or gaps. Pressure was exerted at several points on the plate with a small wooden slat for this same purpose. The slat was drawn across the guides to ensure that the thickness of the adhesive was as specified. The excess resin was subsequently removed. A steel roller was then run across the adhesive and the excess adhesive again removed. Finally, a steel

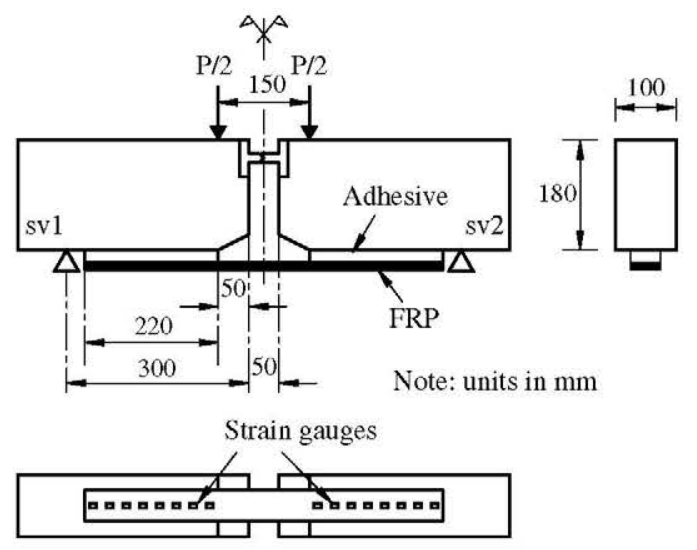

Fig. 1. Experimental setup

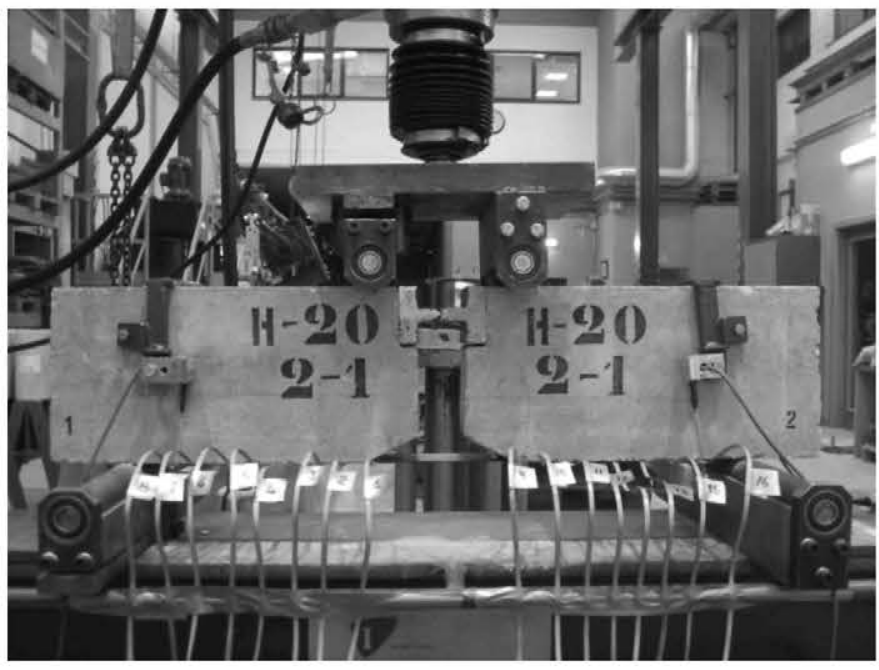

Fig. 2. Specimen H202-1

Table 1. Test Specimens

\begin{tabular}{lcc}
\hline $\begin{array}{l}\text { Nominal concrete } \\
\text { strength }(\mathrm{MPa})\end{array}$ & Adhesive thickness $(\mathrm{mm})$ & $\begin{array}{c}\text { Specimen } \\
\text { series name }\end{array}$ \\
\hline 20 & 2 & $\mathrm{H} 202$ \\
& 3 & $\mathrm{H} 203$ \\
40 & 2 & $\mathrm{H} 402$ \\
60 & 3 & $\mathrm{H} 403$ \\
& 2 & $\mathrm{H} 602$ \\
& 3 & $\mathrm{H} 603$ \\
\hline
\end{tabular}

Table 2. Mechanical Properties

\begin{tabular}{lcccc}
\hline Material & $\begin{array}{c}\text { Compressive } \\
\text { strength } \\
(\mathrm{MPa})\end{array}$ & $\begin{array}{c}\text { Young's } \\
\text { modulus } \\
(\mathrm{GPa})\end{array}$ & $\begin{array}{c}\text { Tensile } \\
\text { strength } \\
(\mathrm{MPa})\end{array}$ & $\begin{array}{c}\text { Elongation } \\
(\%)\end{array}$ \\
\hline Concrete C20 & $27.15^{\mathrm{a}}$ & - & - & - \\
Concrete C40 & $46.2^{\mathrm{a}}$ & - & - & - \\
Concrete C60 & $68.6^{\mathrm{a}}$ & - & - & - \\
FRP plate & - & $165^{\mathrm{b}}$ & $3,100^{\mathrm{b}}$ & $1.7^{\mathrm{b}}$ \\
Adhesive & - & $11.2^{\mathrm{c}}$ & $18-21^{\mathrm{d}}$ & - \\
\hline
\end{tabular}

${ }^{\mathrm{a} O n}$ the day tested, pursuant to Spanish and European standard UNE-EN 12390-3:2009 (UNE-EN 2009).

${ }^{b}$ Pursuant to European standard UNE-EN 2561 (UNE-EN 1996).

${ }^{\mathrm{c}}$ Pursuant ISO 527-2 (ISO 1993).

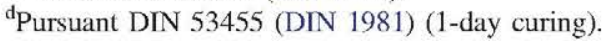

clamp was placed on the side guides in each half-beam to prevent any accidental repositioning. Eight strain gauges were uniformly spaced along the bond length on each half-beam. The tests were conducted after the FRP plates had been in place for 7 days.

Load steps of 0.15 MPa were applied, a value defined in terms of the constant increment in mean bond stress. Loads were ramped up to the next step in $30 \mathrm{~s}$, and allowed to stabilize for $2 \mathrm{~min}$ at each step. The gauge readings, 10 per s, were logged with a computerized data acquisition system.

\section{Results}

\section{Failure Modes}

All the specimens exhibited at least one of the following types of failure: 
1. Concrete failure, in which the FRP laminate was essentially covered by the adhesive and an approximately even layer of concrete measuring 1-2 mm thick.

2. Failure at the adhesive-concrete interface, in which the FRP was essentially covered by the adhesive, with occasional patches of concrete.

3. Failure at the FRP-adhesive interface, in which the FRP surface was clean, with no traces of adhesive.

4. Transverse adhesive failure, in which the adhesive split apart perpendicularly to the laminate.

The H202 and H203 specimens exhibited type 1 failure along the entire bond length. Type 2 failure was observed in the $\mathrm{H} 402$ specimens, whereas the $\mathrm{H} 403$ samples exhibited type 1 failure or a combination of types 1,3 , and 4 . The $\mathrm{H} 602$ specimens were characterized by a combination of failure types 2,3 , and 4 , and the H603 series by a combination of types 1,3 , and 4 . One specimen of each series is depicted in Fig. 3.

\section{Ultimate Load}

Ultimate load varied clearly with concrete strength and adhesive thickness. Greater adhesive thickness did not consistently translate into higher failure loads. The debonding strength was slightly greater in the $\mathrm{H} 202$ than in the $\mathrm{H} 203$ specimens, for instance, a finding attributed to the fact that failure was governed by concrete strength. Fig. 4 plots the axial force on the FRP plate at the debonding load versus concrete strength, while Table 3 gives $P_{u}$, the ultimate load, recorded by the load frame; $F_{p u}$, the equivalent force on the plate, obtained by force equilibrium assuming a $153 \mathrm{~mm}$ lever arm; $\tau_{m}$, the mean bond stress (found by dividing the force on the plate by the bond area); and the mean bond stress for each concrete family. The curves in Fig. 4 show the estimated bond strength obtained for each adhesive thickness [Eq. (1)], whereas the mean bond stress values were found with $\mathrm{Eq}$. (2).

$$
F_{p u}=\left\{\begin{array}{cc}
3.853 f_{c}^{0.56} & \text { for } t_{a}=2 \mathrm{~mm} \\
1.161 f_{c}^{0.9} & \text { for } t_{a}=3 \mathrm{~mm}
\end{array}\right.
$$

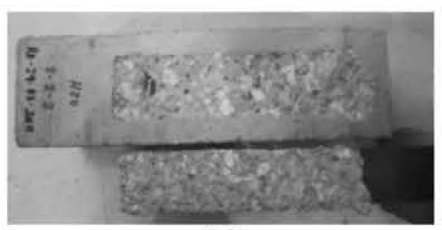

(a)

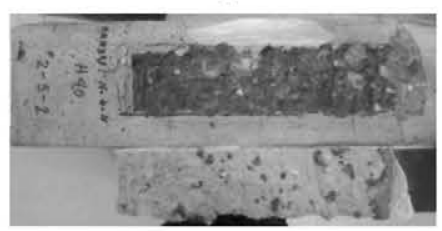

(c)

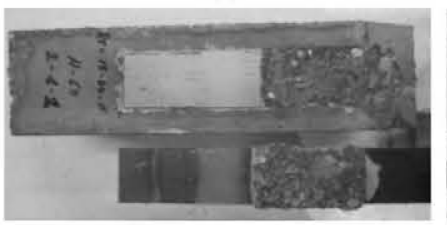

(e) (b)

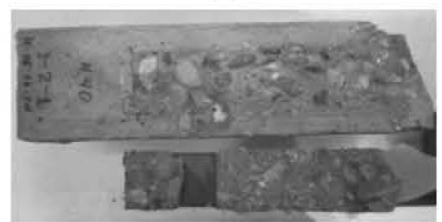

(d)

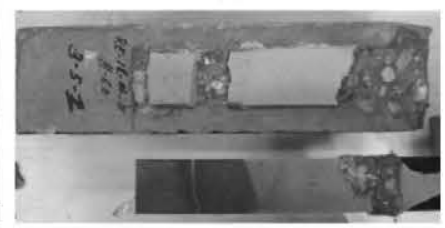

(f)

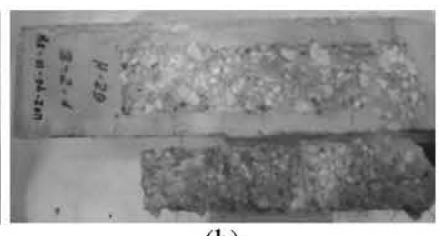

Fig. 3. Failure types: (a) H202 series specimen; (b) H203 series specimen; (c) H402 series specimen; (d) H403 series specimen; (e) H602 series specimen; (f) H603 series specimen

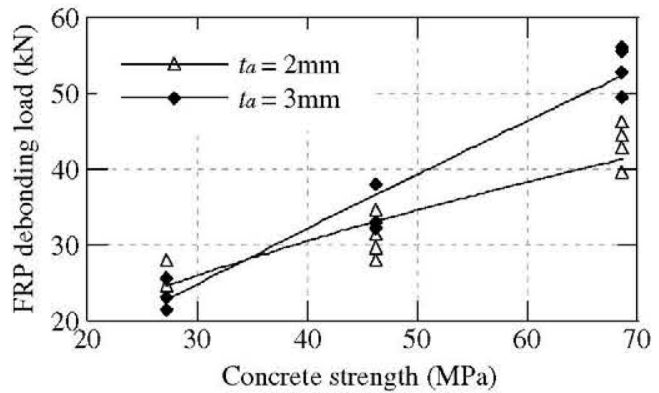

Fig. 4. FRP debonding load versus concrete strength

$$
\tau_{m}=\left\{\begin{array}{cl}
0.350 f_{c}^{0.56} & \text { for } t_{a}=2 \mathrm{~mm} \\
0.106 f_{c}^{0.9} & \text { for } t_{a}=3 \mathrm{~mm}
\end{array}\right.
$$

In the $\mathrm{H} 403$ series, transverse failure was observed in the adhesive layer before debonding took place. This induced stress redistribution and eventually plate detachment. Analogously, transverse failure in the adhesive was observed in the entire H60 family before debonding. In this case, the specimens continued to resist load increments essentially because their effective bond length was shorter than in the H40 specimens. Moreover, because the H60 specimens were made from stronger concrete, the FRPconcrete interface resisted the stress redistribution generated by the transverse failure of the adhesive.

\section{Bond Stress and Stress-Slip Relationship}

One common method for finding interface shear stress is to calculate the mean stress from the difference in the strain in two consecutive gauges. With this procedure, however, the number of points at which shear stress can be obtained depends on the number and position of the strain gauges. The present study applied a nonparametric, shape-preserving fitting procedure to obtain strain on the plates from the gauge readings along the entire bond length. This method was chosen because it preserves data monotonicity and shape. Multiplying the derivative of the fit at a specific point by FRP thickness and the modulus of deformation yields an approximate value of the shear stress at that point. Fig. 5 shows the strain on the FRP plate in one specimen in each series for a load ratio of $P / P_{u}=0.8$. Figs. 6-11, in turn, show the shear stress distribution for all the specimens in each series for the aforementioned load ratio. That stress level was chosen because it was both sufficiently close to the failure load and representative of the stress distribution prior to transverse failure in the adhesive.

Stress was observed to concentrate in the area around the inner edge in all the specimens. As previously noted, concrete was the

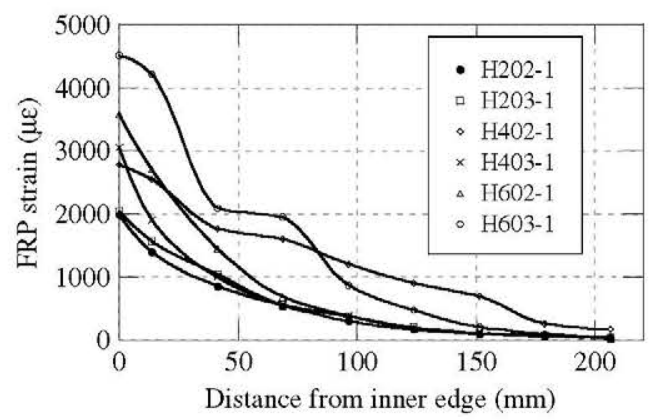

Fig. 5. FRP strain at $P / P_{u}=0.8$ 


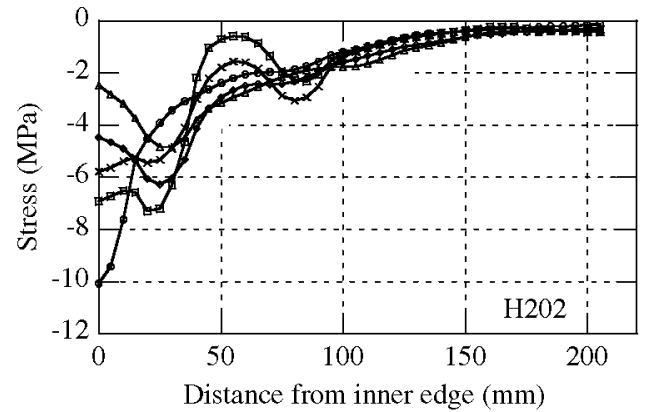

Fig. 6. Shear stress in $\mathrm{H} 202$ specimens at $P / P_{u}=0.8$

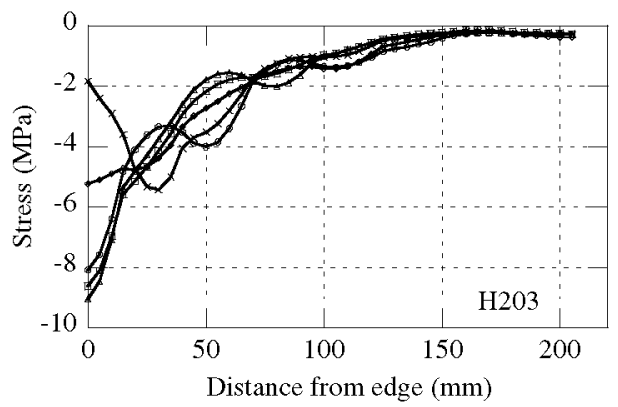

Fig. 7. Shear stress in $\mathrm{H} 203$ specimens at $P / P_{u}=0.8$

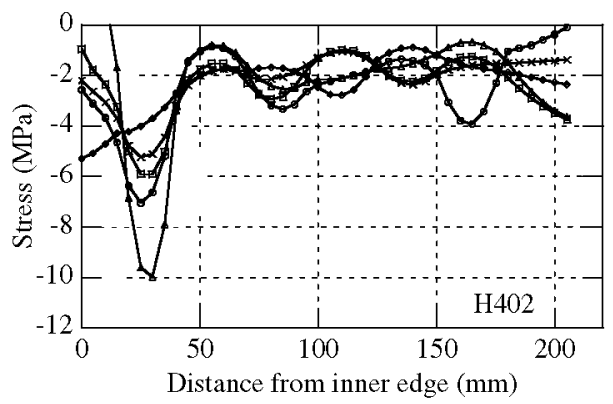

Fig. 8. Shear stress in $\mathrm{H} 402$ specimens at $P / P_{u}=0.8$

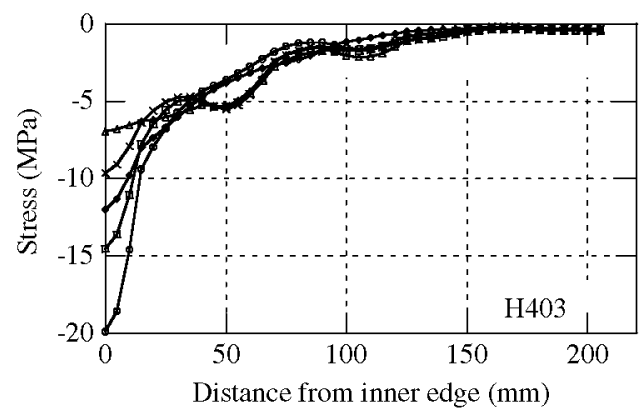

Fig. 9. Shear stress in $\mathrm{H} 403$ specimens at $P / P_{u}=0.8$

element that failed in all the $\mathrm{H} 20$ series specimens. Concrete weakening (microcracking) began at peak stress, which rapidly led to deterioration and sudden failure because of the low tensile strength of this material.

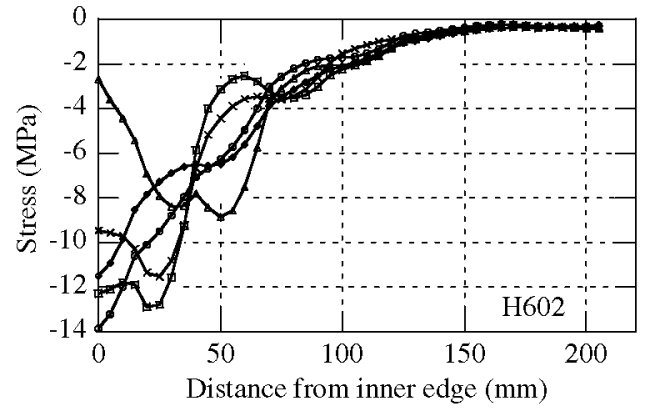

Fig. 10. Shear stress in $\mathrm{H} 602$ specimens at $P / P_{u}=0.8$

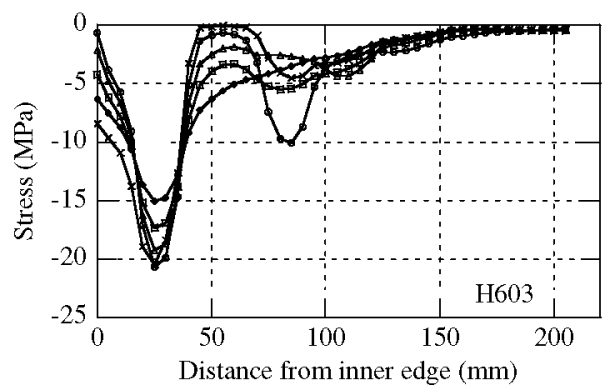

Fig. 11. Shear stress in $H 603$ specimens at $P / P_{u}=0.8$

In the H402 specimens, concrete microcracking and concomitant weakening was concentrated in an area between 0 and $35 \mathrm{~mm}$ from the edge. Because tensile strength was higher in this concrete, damage did not spread as readily as in the $\mathrm{H} 20$ family, and the thin layer of adhesive prevented stress redistribution along the bond length. The resulting concentration at the edge eventually exceeded concrete tensile strength at the weakest points and concrete-adhesive bond strength (failure at the adhesive-concrete interface).

By the time the applied load reached $90 \%$ of the ultimate load, the adhesive had failed transversally in specimens H6022, H6023, $\mathrm{H} 6024$, and H6025. This induced stress redistribution and reduction of the bond length. In other words, the adhesive conditioned the debonding load. Because the adhesive was thicker in the $\mathrm{H} 603$ series, the failure load was considerably higher in that family. Transverse adhesive failure was attributed to the concentration of shear and normal stresses at high load levels. This development was observed primarily in the H60 family for that reason.

Because stress was observed to concentrate in the area near the inner edge, the analysis of damage to the bond throughout the loading process is given for the cross section located at $30 \mathrm{~mm}$ from the inner edge in the half-beams that failed. The slip can be calculated by integrating the nonparametric fit under the assumption that the strain on the concrete substrate was negligible. The points shown in Figs. 12-17 refer to $\tau-\delta$ pairs obtained from the nonparametric fit for strain gauge readings logged at 15 -s intervals through specimen failure.

The approach used to obtain the bond stress-slip relationship is known by the scientific community (Faella et al. 2009) as the direct method that, according to those authors, depends on the number and position of strain readings on the FRP laminate. In the present study, the inherent variability in FRP-concrete bond failure was accommodated by the number of gauges installed and the interpolation method and number of specimens used. 


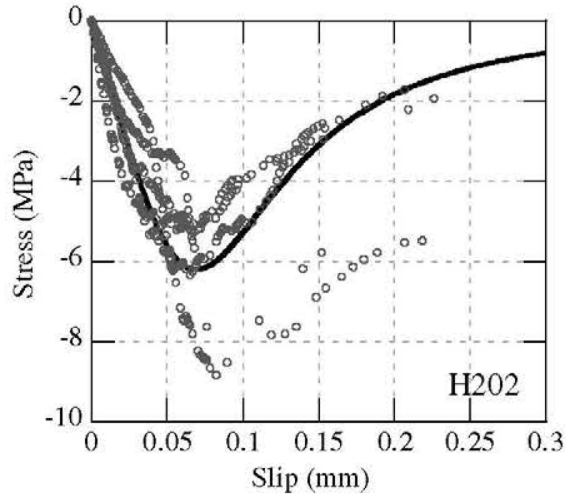

Fig. 12. $\tau-\delta$ relationship at $30 \mathrm{~mm}$ from the edge in the $\mathrm{H} 202$ series specimens

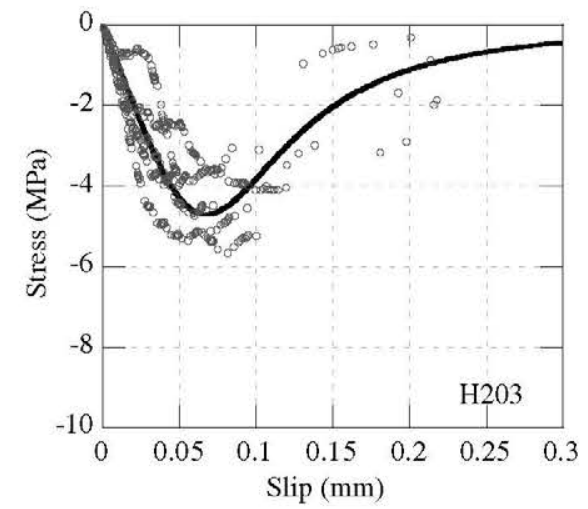

Fig. 13. $\tau-\delta$ relationship at $30 \mathrm{~mm}$ from the edge in the $\mathrm{H} 203$ series specimens

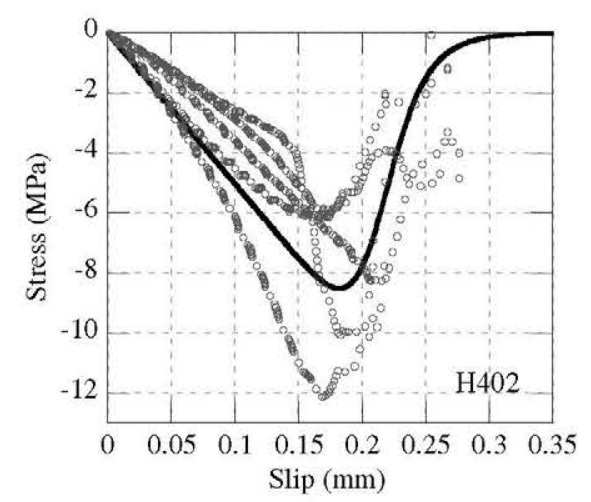

Fig. 14. $\tau-\delta$ relationship at $30 \mathrm{~mm}$ from the edge in the $\mathrm{H} 402$ series specimens

A number of authors (Nakaba et al. 2001; Mazzotti et al. 2009) have used the Popovics (1973) equation [Eq. (3)] to fit the stress-slip relationship, which is reflected reasonably well in the model. This equation was also used in the present study, where $\tau_{\max }$ and $\delta_{0}=$ mean values found for the five half-beams comprising the family studied. Parameter $n$ was obtained by least squares.

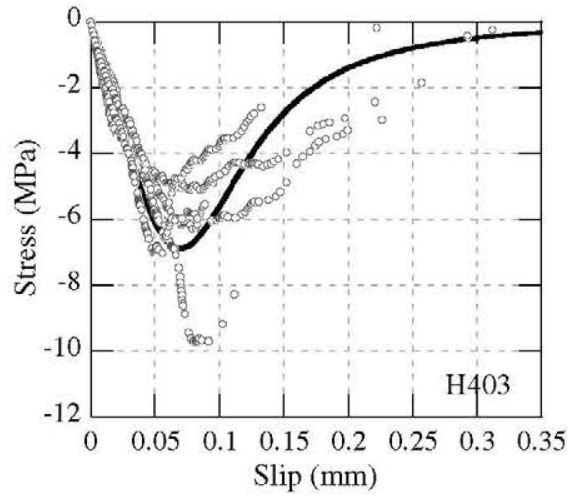

Fig. 15. $\tau-\delta$ relationship at $30 \mathrm{~mm}$ from the edge in the $\mathrm{H} 403$ series specimens

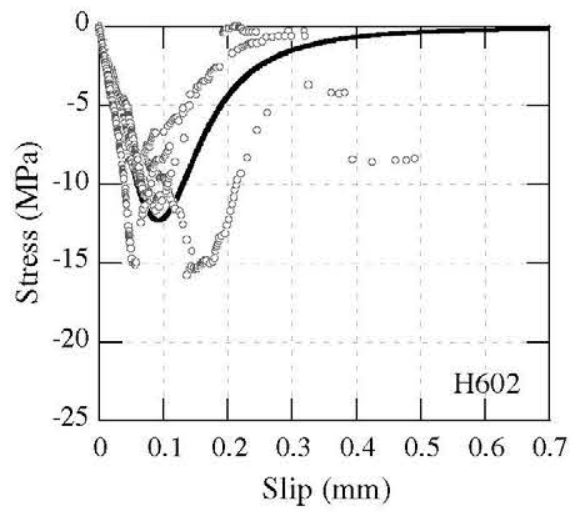

Fig. 16. $\tau-\delta$ relationship at $30 \mathrm{~mm}$ from the edge in the $\mathrm{H} 602$ series specimens

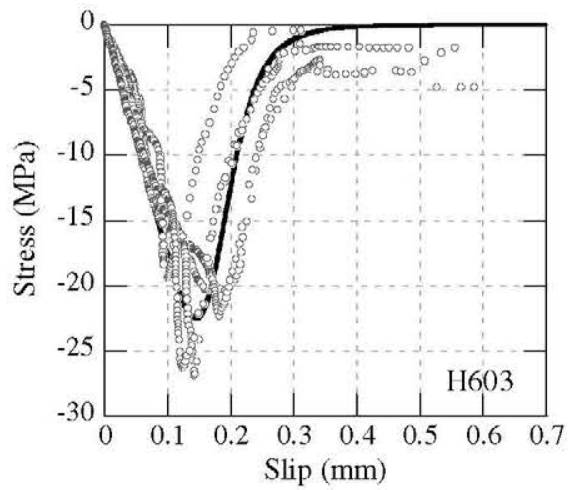

Fig. 17. $\tau-\delta$ relationship at $30 \mathrm{~mm}$ from the edge in the $\mathrm{H} 603$ series specimens

$$
\tau=\tau_{\max } \frac{\delta}{\delta_{0}}\left(\frac{n}{(n-1)+\left(\delta / \delta_{0}\right)^{n}}\right)
$$

The result, as illustrated in Figs. 12-17, was a fairly good fit. Parameters of each family are listed in Table 4.

In the $\mathrm{H} 203$ series specimens, the softening branch of the bond stress-slip relationship was observed to decline more steeply than in 
Table 3. Ultimate Load and Mean Stress

\begin{tabular}{|c|c|c|c|c|}
\hline Specimen & $P_{u}(\mathrm{kN})$ & $F_{p u}(\mathrm{kN})$ & $\tau_{m}(\mathrm{MPa})$ & Mean $\tau_{m}(\mathrm{MPa})$ \\
\hline $\mathrm{H} 202-1$ & 30.30 & 24.75 & 2.25 & \\
\hline $\mathrm{H} 202-2$ & 30.30 & 24.75 & 2.25 & \\
\hline $\mathrm{H} 202-3$ & 34.34 & 28.05 & 2.55 & 2.33 \\
\hline H202-4 & 30.30 & 24.75 & 2.25 & \\
\hline $\mathrm{H} 202-5$ & 30.30 & 24.75 & 2.25 & \\
\hline $\mathrm{H} 203-1$ & 31.33 & 25.59 & 2.33 & \\
\hline $\mathrm{H} 203-2$ & 28.28 & 23.10 & 2.10 & \\
\hline $\mathrm{H} 203-3$ & 28.28 & 23.10 & 2.10 & 2.12 \\
\hline H203-4 & 26.26 & 21.45 & 1.95 & \\
\hline $\mathrm{H} 203-5$ & 28.28 & 23.10 & 2.10 & \\
\hline $\mathrm{H} 402-1$ & 42.42 & 34.65 & 3.15 & \\
\hline $\mathrm{H} 402-2$ & 38.38 & 31.35 & 2.85 & \\
\hline $\mathrm{H} 402-3$ & 36.36 & 29.70 & 2.70 & 2.79 \\
\hline $\mathrm{H} 402-4$ & 36.36 & 29.70 & 2.70 & \\
\hline $\mathrm{H} 402-5$ & 34.34 & 28.05 & 2.55 & \\
\hline H403-1 & 46.46 & 37.95 & 3.45 & \\
\hline $\mathrm{H} 403-2$ & 46.46 & 37.95 & 3.45 & \\
\hline $\mathrm{H} 403-3$ & 40.40 & 33.00 & 3.00 & 3.16 \\
\hline $\mathrm{H} 403-4$ & 39.32 & 32.12 & 2.92 & \\
\hline $\mathrm{H} 403-5$ & 40.40 & 33.00 & 3.00 & \\
\hline $\mathrm{H} 602-1$ & 54.53 & 44.55 & 4.05 & \\
\hline $\mathrm{H} 602-2$ & 56.55 & 46.20 & 4.20 & \\
\hline H602-3 & 52.51 & 42.90 & 3.90 & 3.93 \\
\hline $\mathrm{H} 602-4$ & 52.51 & 42.90 & 3.90 & \\
\hline $\mathrm{H} 602-5$ & 48.48 & 39.60 & 3.60 & \\
\hline H603-1 & 68.67 & 56.10 & 5.10 & \\
\hline $\mathrm{H} 603-2$ & 68.67 & 56.10 & 5.10 & \\
\hline $\mathrm{H} 603-3$ & 64.63 & 52.80 & 4.80 & 4.91 \\
\hline $\mathrm{H} 603-4$ & 60.59 & 49.50 & 4.50 & \\
\hline H603-5 & 68.06 & 55.60 & 5.05 & \\
\hline
\end{tabular}

Table 4. Parameters of Stress-Slip Relationship

\begin{tabular}{lccr}
\hline Specimen series name & $\tau_{\max }(\mathrm{MPa})$ & $\delta_{0}(\mathrm{~mm})$ & \multicolumn{1}{c}{$n$} \\
\hline H202 & -6.20 & 0.0693 & 3.25 \\
H203 & -4.71 & 0.0675 & 3.40 \\
H402 & -8.51 & 0.1820 & 14.61 \\
H403 & -6.87 & 0.0697 & 3.72 \\
H602 & -12.28 & 0.0917 & 4.00 \\
H603 & -22.48 & 0.1450 & 7.98 \\
\hline
\end{tabular}

the specimens with $2 \mathrm{~mm}$ of adhesive. This was obvious because the number of points following peak stress was clearly smaller, and consistent with the lower failure load observed for the $\mathrm{H} 203$ series specimens.

In the $\mathrm{H} 402$ series (Fig. 14), the slip value, $\delta_{0}$, reached at peak stress was greater than in any of the other series. After peak stress, the softening branch declined steeply. This was attributed to the fact that the bond between the adhesive and the concrete was unable to efficiently transfer stress to the concrete. This behavior largely determined adhesive-concrete bond strength, as deduced from the failure mode in these specimens. Contrary to the $\mathrm{H} 402$ specimen behavior, in the $\mathrm{H} 403$ series (Fig. 15), the softening branch did not decline abruptly, and slip, $\delta_{0}$, was smaller, an indication that the adhesive-concrete bond was able to transfer the stress to the concrete. For that reason, it was the concrete, rather than the adhesive-concrete interface as in the $\mathrm{H} 402$ series, that failed in most of the $\mathrm{H} 403$ samples. This is consistent with the clearly higher mean slip, $\delta_{0}$, in series $\mathrm{H} 402$ than in series $\mathrm{H} 403$ (Table 4).

As previously mentioned, the ultimate load in the $\mathrm{H} 602$ specimens was conditioned by the adhesive. The same inference may be drawn for the peak stress and slip, $\delta_{0}$ (Fig. 16). In this vein, the

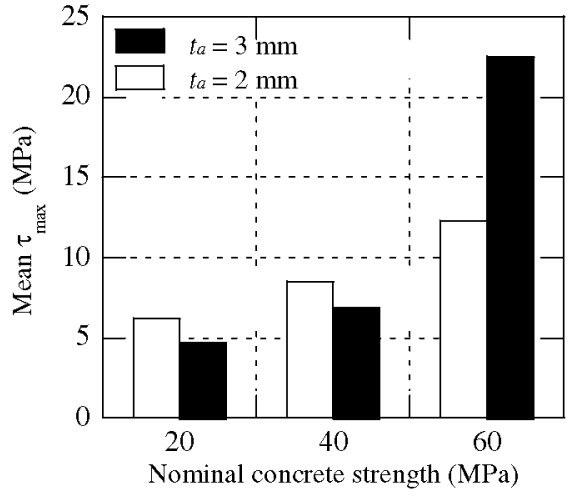

Fig. 18. Mean $\tau_{\max }$

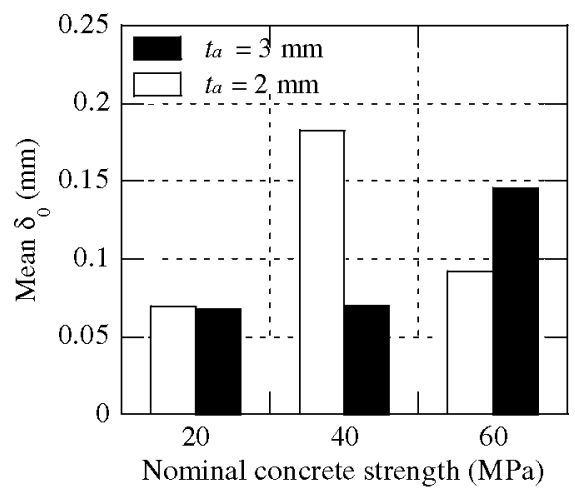

Fig. 19. Mean $\delta_{0}$

stress-slip relationship parameters, particularly peak stress, exhibited higher values in the H603 (Fig. 17) than in the H602 series specimens (Figs. 18 and 19).

\section{Conclusions}

The FRP-concrete bonding in beam-type tests was studied in detail. The experimental findings and their analysis contribute to a better understanding of debonding and stress transfer in such tests. The stress-slip relationship was analyzed in a cross section near the inner edge, where stress was observed to concentrate in all cases. The following conclusions can be drawn from the findings:

- The test method proposed for characterizing FRP-concrete bonding is valid across a range of concrete strengths and adhesive thicknesses, and delivers more accurate information on FRP-strengthened beam behavior than the procedures presently in place. It may be useful for studying different types of adhesives and application methods, or even the effect on bonding of concrete altered by freeze-thaw or other types of environmental aggression, by reproducing such conditions in the specimens. Moreover, in this test, the free end of the FRP does not have to be restrained as is generally the case in the single shear test.

- The nonparametric fitting of the experimental readings suggests that in low-strength concrete members, failure occurs in the weakest system component, i.e., the concrete, and is unrelated to adhesive thickness, as reflected in the similarity between the curves in Figs. 12 and 13. These same findings appear to show that in higher strength concrete, failure occurs at the weakest system component, which in this case is the concrete-adhesive 
interface. Here, where the adhesive would play a more significant role, greater thickness would favor stress redistribution and raise the ultimate load.

- The bond stress-slip relationship was found for the area around the inner edge, where stress was concentrated. The generally narrower scatter observed for the $\mathrm{H} 403$ and H603 specimens denoted more effective stress transfer. The equation originally proposed by Popovics (1973) provided a good fit for the stress-slip relationship in all the series studied.

\section{Acknowledgments}

This research was funded by the Instituto Técnico de Materiales y Construcciones (INTEMAC). Special thanks are due to its Central Laboratory staff for their support in the experimental part of this study and to BETAZUL for the FRP material used in this research.

\section{Notation}

The following symbols are used in this paper:

$F_{p u}=$ debonding force on the strengthening material;

$P_{u}=$ ultimate load reached in the beam test;

$t_{a}=$ adhesive thickness;

$\delta=$ slip;

$\delta_{0}=$ slip at peak shear stress;

$\tau=$ shear stress;

$\tau_{m}=$ mean bonding stress; and

$\tau_{\max }=$ peak shear stress.

\section{References}

American Concrete Institute (ACI). (2004). "Test methods for FRP laminates for concrete and masonry." ACI 440.3R-04, Farmington Hills, MI.

ASTM. (2009). "Standard test method for pull-off strength for FRP bonded to concrete substrate." D7522/D7522M-09, West Conshohocken, PA.

Cao, S. Y., Chen, J. F., Pan, J. W., and Sun, N. (2007). "ESPI measurement of bond-slip relationships of FRP-concrete interface." J. Compos. Constr., 11(2), 149-160.

Deutsches Institut fur Normung (DIN). (1981). "Testing of plastics; tensile test." DIN 53455, Berlin.

Faella, C., Martinelli, E., and Nigro, E. (2009). "Direct versus indirect method for identifying FRP-to-concrete interface relationships." J. Compos. Constr., 13(3), 226-233.

Ferracuti, B., Savoia, M., and Mazzotti, C. (2007). "Interface law for FRP—concrete delamination." Compos. Struct., 80(4), 523-531.

Foster, S. J., and Khomwan, N. (2005). "Determination of bond stress versus slip for externally bonded FRP from standardised bond strength tests." Bond Behaviour of FRP in Structures: Proc., Int. Symp. BBFS, International Institute for FRP in Construction, Hong Kong, 85-90.

Guo, Z. G., Cao, S. Y., Sun, W. M., and Lin, X. Y. (2005). "Experimental study on bond stress-slip behaviour between FRP sheets and concrete." Bond Behaviour of FRP in Structures: Proc., Int. Symp. BBFS, International Institute for FRP in Construction, Hong Kong, 77-83.

Horiguchi, T., and Saeki, N. (1997). "Effect of test methods and quality of concrete on bond strength of CFRP sheet." Non-Metallic (FRP) Reinforcement for Concrete Structures: Proc., Third Int. Symp., Japan Concrete Institute, Japan, Vol. 1, 265-270.

ISO. (1993). "Plastics-determination of tensile properties-part 2: Test conditions for moulding and extrusion plastics." ISO 527-2, Geneva.
Leung, C. K. Y., Klenke, M., Tung, W. K., and Luk, H. C. Y. (2006). "Determination of nonlinear softening behavior at FRP composite/ concrete interface." J. Eng. Mech., 132(5), 498-508.

López, J., Fernández, J., and González, E. (2011). "Influencia de la relación tensión-deslizamiento en el comportamiento de la interfase FRPhormigón." Proc., IX Congreso Nacional de Materiales Compuestos, Asociación Española de Materiales Compuestos, Spain, 801-806.

Mazzotti, C., Savoia, M., and Ferracuti, B. (2009). "A new single-shear set-up for stable debonding of FRP-concrete joints." Constr. Build. Mater., 23(4), 1529-1537.

Nakaba, K., Kanakubo, T., Furuta, T., and Yoshizawa, H. (2001). "Bond behavior between fiber-reinforced polymer laminates and concrete." ACI Struct. J., 98(3), 359-367.

Oller, E. (2005). "Peeling failure in beams strengthened by plate bonding. A design proposal." Ph.D. thesis, Universitat Politecnica De Catalunya, Barcelona, Spain.

Perera, R., Recuero, A., Diego, A. D., and López, C. (2004). "Adherence analysis of fiber-reinforced polymer strengthened RC beams." Comput. Struct., 82(23-26), 1865-1873.

Popovics, S. (1973). "A numerical approach to the complete stress-strain curve of concrete." Cem. Concr. Res., 3(5), 583-599.

Rabinovich, O., and Frostig, Y. (2000). "Closed-form high-order analysis of RC beams strengthened with FRP strips." J. Compos. Constr., 4(2), $65-74$.

Sharma, S. K., Mohamed Ali, M. S., Goldar, D., and Sikdar, P. K. (2006). "Plate-concrete interfacial bond strength of FRP and metallic plated concrete specimens." Compos. Part B: Eng., 37(1), 54-63.

Shen, H., Teng, J. G., and Yang, J. (2001). "Interfacial stresses in beams and slabs bonded with thin plate." J. Eng. Mech., 127(4), 399-406.

Teng, J. G., Yuan, H., and Chen, J. F. (2006). "FRP-to-concrete interfaces between two adjacent cracks: Theoretical model for debonding failure." Int. J. Solids Struct., 43(18-19), 5750-5778.

Tounsi, A., and Benyoucef, S. (2007). "Interfacial stresses in externally FRP-plated concrete beams." Int. J. Adhes. Adhes., 27(3), 207-215.

Tounsi, A., Hassaine Daouadji, T., Benyoucef, S., and Adda bedia, E. A. (2009). "Interfacial stresses in FRP-plated RC beams: Effect of adherend shear deformations." Int. J. Adhes. Adhes., 29(4), 343-351.

Toutanji, H., Saxena, P., Zhao, L., and Ooi, T. (2007). "Prediction of interfacial bond failure of FRP-concrete surface." J. Compos. Constr., 11(4), 427-436.

UNE-EN. (1996). "Aerospace series. Carbon fiber reinforced plastics. Unidirectional laminates. Tensile test parallel to the fiber direction." UNE-EN 2561, Madrid.

UNE-EN. (2006). "Steel for the reinforcement of concrete-weldable reinforcing steel-general." UNE-EN 10080, Madrid.

UNE-EN. (2009). "Testing hardened concrete-part 3: Compressive strength of test specimens." UNE-EN 12393-3:2009/AC:2011, Madrid.

Wan, B. L., Sutton, M. A., Petrou, M. F., Harries, K.A., and Ning, U. (2004). "Investigation of bond between fiber reinforced polymer and concrete undergoing global mixed mode I/II loading." J. Eng. Mech, $130(12), 1467-1475$.

Wang, J. (2006a). "Cohesive zone model of intermediate crack-induced debonding of FRP-plated concrete beam." Int. J. Solids Struct., 43(21), $6630-6648$.

Wang, J. (2006b). "Debonding of FRP-plated reinforced concrete beam, a bond-slip analysis. I. Theoretical formulation." Int. J. Solids Struct., 43(21), 6649-6664.

Yang, J., Ye, J., and Niu, Z. (2007). "Interfacial shear stress in FRP-plated RC beams under symmetric loads." Cem. Concr. Compos., 29(5), 421-432.

Yao, J., Teng, J. G., and Chen, J. F. (2005). "Experimental study on FRPto-concrete bonded joints." Compos. Part B: Eng., 36(2), 99-113. 